\section{Factors that Determine Preschool Teacher Self-Efficacy in an Urban School District}

\author{
Charles J. INFURNA ${ }^{1, *}$, Donna RITER ${ }^{2}$, Susan SCHULTZ
}

\begin{tabular}{ll}
\hline Received: & 09 July 2018 \\
Revised: $\quad 08$ August 2018 \\
Accepted: $\quad 31$ August 2018 \\
ISSN: 1307-9298 \\
Copyright (C) IEJEE \\
www.iejee.com
\end{tabular}

DOI: $10.26822 /$ iejee.2018143929

\begin{abstract}
The aim of the present study is to determine what teacher variables are predictive of preschool teacher self-efficacy in an urban school district. A total of 83 preschool teachers participated in the study. Teacher variables, such as years of teaching experience, job satisfaction, location of employment, age, and self-efficacy were included in a series of ANOVA analyses. Linear regression modeling reported years of teaching experience outside the birth-2nd grade setting $(\beta=-.232, t(1,79)=$ $-2.124, p<.05)$ and job satisfaction $(\beta=.294, t(2,78)=2.793, p<.01)$ were statistically significant predictors of preschool teacher self-efficacy. This study found that teachers with a greater amount of teaching experience outside of the birth-2nd setting feel less efficacious about themselves and their abilities to positively influence student achievement and outcomes in the preschool classroom. Further policy implications, such as hiring practices are discussed.
\end{abstract}

Key words: Early childhood education, Self-efficacy, Job satisfaction, Preschool teacher, Classroom outcomes.

\section{Introduction}

Federal and state governments have begun investing more funding in the support of high-quality preschool programming. In the 2016-17 school year, New York State allocated over $\$ 300$ million in support of full-day Universal Pre-Kindergarten programming (New York State Education Department; NYSED, 2016). Lynch and Vaghul (2015) report numerous benefits from investing public funds into high-quality pre-kindergarten programing. Some of which include higher assessment scores during the elementary aged years, fewer special education referrals, and a decreased likelihood of repeating a grade during the elementary years. High quality preschool programming has also been associated with positive developmental outcomes of young children as they transition through elementary, to middle, and eventually to high school (Mashburn et al., 2008; Meisels, 2006), such as social-emotional functioning and regulation.

In light of the relationship between early childhood education experiences and developmental outcomes, empirical studies have not specifically explored the aspects of the early childhood education environment that are associated with student outcomes (Guo et al., 2011a). Recently, one aspect of early childhood education programming that has begun to draw researcher attention is teacher self-efficacy (Guo, Piasta, Justice, \& Kaderavek, 2010; Justice, Mashburn, Hamre, \& Pianta, 2008). Teacher self-efficacy is broadly defined as a "teacher's belief in his or her own capability to organize and execute courses of action required to successfully accomplish a specific teaching task in a particular context" (Tschannen-Moran, Woolfolk Hoy, \& Hoy, 1998, p. 233). A better understanding of the factors that influence teacher self-efficacy may be crucial to ensuring the quality and effectiveness of preschool teaching. Being able to identify specific variables that may be attributable to teacher self-efficacy would shed some light on informing efforts to increase teacher self-efficacy, specific to preschool teachers (Guo et al., 2011a; 2010).
The purpose of this study is to examine preschool teacher characteristics may be associated with and predictors of self-efficacy. In this study, we examined such teacher variables such as; years of teaching experience, job satisfaction, and place of employment (school district or community based organization). Previous studies also examined teacher-child interactions as a variable that positively (Justice et al., 2008; Guo et al., 2010) influenced teacher self-efficacy. We also examined how observed classroom quality may be predictive of preschool teacher self-efficacy.

\section{Factors associated with preschool teacher self-efficacy}

Previous researchers have suggested that teacher characteristics, such as teaching experience, certification type, and location of programming may affect a teachers' sense of efficacy (Wolters \& Daugherty, 2007). Wolters and Daugherty (2007) found a positive correlation between teacher self-efficacy and years of teaching experience K-12. Research conducted on American teachers found that preschool through $12^{\text {th }}$ grade teachers with more years of teaching experience had reported a higher sense of efficacy. Similarly, Cheung (2008) found that for both Hong Kong and Shanghai elementary school teachers, longer teaching experience was a significant predictor of higher teacher self-efficacy. Corroborating previous studies, Kim and Kim (2010) found a strong positive relationship between years of teaching experience and teacher self-efficacy $(r=.20)$. In a study conducted on Canadian preschool teachers, Bullock and colleagues (2015) reported that teachers with more years of teaching experience had higher levels of classroom management teacher self-efficacy $(r=.21)$. However, in contrast, Guo et al. (2010) reported that preschool teachers having more years of preschool teaching experience negatively correlated with their self-reported self-efficacy $(r=-.29)$.

An area of the literature that has been less explored is

Corresponding Author: Children's Institute, 274 North Goodman Street Suite D103, Rochester, NY 14607, USA. St. John Fisher College, 3690 East Avenue, Rochester, NY, 14618, USA. E-mail: cinfurna@childrensinstitute.net Phone: (585) 406 - 1399

2 St. John Fisher College, 3690 East Avenue, Rochester, NY, 14618, USA. E-mail driter@sjfc.edu, Phone: (585) $704-4343$

${ }^{3}$ St. John Fisher College, 3690 East Avenue, Rochester, NY, 14618, USA. E- mail sschultz@sjfc.edu Phone 716 ) 472 - 4580

(c) 2018 Published by T\& K Academic. This is an open access article under the CC BY- NC- ND license. (https://creativecommons.org/licenses/by/4.0/) 
whether the location of programming is associated with teacher self-efficacy. Many previous studies conducted with preschool teachers has been focused on urban (Guo et al. 2011a; 2010) or Head Start settings (Early et al. 2007; Justice et al. 2008). The research has failed to identify how teacher self-efficacy may be affected by whether the preschool teacher is an employee of a public school district, or an employee of a community based organization (CBO) such as Head Start.

\section{Job Satisfaction}

Job satisfaction is broadly defined as either positive or negative judgments people make about their current position of employment (Weiss, 2002). Van den Berg (2002) and Chen (2007) have indicated that job satisfaction is an important teacher characteristic with teachers' relationships with students and teachers' enthusiasm towards teaching. Avanzi and colleagues (2013) reported that job satisfaction was associated with higher teacher self-efficacy. Similarly, in a sample of elementary and middle school teachers, Skaalvik and Skaalvik (2014) found job satisfaction was positively associated with teacher self-efficacy. The current literature lacks studies that have examined preschool teacher job satisfaction and self-efficacy.

\section{Teacher Outcomes}

Goddard and Goddard (2001) report that developmentally appropriate classroom best practices are found to have a positive relationship with teacher self-efficacy. In other words, teacher self-efficacy indirectly affects student achievement through high quality teacher-child interactions. One way in which preschool teacher classroom quality has previously been measured has been by the administration of the Classroom Assessment Scoring System (CLASS Pianta, La Paro, \& Hamre, 2008). To become a CLASS scorer, one typically attends a two or three-day intensive workshop and pass a test to reliability.

The CLASS is made up of three domains; emotional support (measures the warm and caring interactions a teacher and child have in the classroom), classroom organization (measures classroom management techniques and how children follow classroom norms and routines), and instructional support (the verbal interactions between teachers and their children in the classroom). Teachers who are rated as having high quality teaching environments in which instructional support scores are high engage in frequent feedback loops that are observed between the teacher and child, as well as how concepts of instruction are scaffolded to meet each child's individual needs (Masburn et al., 2008).

The emotional support and instructional support domains of the CLASS have been associated with higher observed student achievement in the empirical research conducted in the United States (Guo et al., 2010; Mashburn et al., 2008; Justice et al., 2008). One such measure of student achievement that has been studied is language and literacy development.

Language and literacy development among preschool children is an important characteristic that has been observed to be impacted by observed high quality teacher child interactions in the classroom (Meisels, 2006). The links between teacher self-efficacy and classroom quality have also been suggested through the findings of several studies (Ashton \& Webb, 1986; Gibson \& Dembo, 1984; Justice et al., 2008). For example, Guo et al., (2010) reported that teacher self-efficacy and high emotional support domain scores of the CLASS were significant predictors of vocabulary knowledge in children.

\section{The Present Study}

The present study examined the extent to which specific preschool teacher characteristics would contribute to teacher self-efficacy. In our study, we examined the relationship between teacher self-efficacy and years of teaching experience, age, job location, and job satisfaction. Similar to previous studies conducted by Guo and colleagues (2010) and Justice and colleagues (2008), we also sought to explore the relationship between teacher self-efficacy and classroom quality measured by the CLASS (Pianta et al., 2008).

\section{Methods}

\section{Participants}

Upon receiving IRB approval from both school district and lead author institution, data from the 2015-16 academic year were used from a larger on-going longitudinal research study examining the early childhood education program of a small to mid-size urban school district in Western New York. In total, 173 teacher demographic questionnaires were distributed to preschool teachers via Survey Monkey in January, 2016.

Of the 173 distributed questionnaires, 124 (72\%) were completed and returned. For the purpose of this study, only teachers that completed the teacher self-efficacy portion of the demographic questionnaire were included (83 or $48 \%$ ). Participants in the present study were all early childhood educators either directly employed by the school district or other community based organizations. The school district receives separate preschool funding for Universal Pre-kindergarten (UPK; 4 year olds) and Early Pre-kindergarten (EPK; 3 year olds) grants. Table 1 provides teacher demographic information.

\section{Measures}

Teacher demographic questionnaire. Teachers were asked to complete the demographic questionnaire via Survey Monkey. They were informed that the completion of the demographic questionnaire was voluntary. Teachers were asked to identify whether they were employed by the school district or CBO, if they were a UPK or EPK teacher, how many years of teaching experience they had, their age, degree(s) earned, certification status, and job satisfaction. Job satisfaction was measured by a single-item measure frequently used in workplace research, but has been also used in a cross-cultural study on teacher self-efficacy (Klassen et al., 2009).

Teacher self-efficacy questionnaire. Teacher self-efficacy was measured by the 24-item, long version of the teacher self-efficacy scale developed by Tschannen-Moran and Woolfolk Hoy (2001). Each item is rated on a 9-point Likert scale (from $1=$ strongly disagree to $9=$ strongly agree). The Teachers Sense of Efficacy Scale (TSES) is comprised of three distinct domains; (a) efficacy for instructional strategies, (b) efficacy for classroom management, and (c) efficacy for student engagement. In previous empirical studies conducted on preschool teacher self-efficacy, the three subscales demonstrated strong scale score reliability and evidence of validity (Brown, 2005; Klassen \& Chiu, 2010; Tschannen-Moran \& Woolfolk Hoy, 2001; 2007).

Teacher outcomes. Teacher outcomes were measured by the CLASS (Pianta et al., 2008). Trained and reliable observers observe a classroom for 20 minutes, then step out of the room and score the cycle. They complete this process five times, for a total of five cycles. Scores from the five completed cycles are averaged to provide domain scores and an overall CLASS score. Four dimensions make 
Table 1. Teacher Demographic Information

\begin{tabular}{|c|c|c|c|}
\hline Variable & $\mathrm{N}$ & Mean & Std. Dev. \\
\hline \multicolumn{4}{|l|}{ Gender } \\
\hline Male & 4 & & \\
\hline Female & 78 & & \\
\hline \multicolumn{4}{|l|}{ Race } \\
\hline American Indian & 1 & & \\
\hline Black & 7 & & \\
\hline Latin & 1 & & \\
\hline White & 67 & & \\
\hline \multicolumn{4}{|l|}{ Ethnicity } \\
\hline Hispanic & 4 & & \\
\hline Not Hispanic & 70 & & \\
\hline Age & 79 & 41.0 & 13.5 \\
\hline \multicolumn{4}{|l|}{ Years of Teaching Experience } \\
\hline Career & 83 & 11.5 & 8.1 \\
\hline Early Childhood & 83 & 10.1 & 7.5 \\
\hline Other ECE & 83 & 2.4 & 4.9 \\
\hline Job Satisfaction & 83 & 7.4 & 1.5 \\
\hline \multicolumn{4}{|l|}{ Program of Employment-Site } \\
\hline School District & 37 & & \\
\hline $\mathrm{CBO}$ & 44 & & \\
\hline \multicolumn{4}{|l|}{ Program Type } \\
\hline UPK & 55 & & \\
\hline EPK & 26 & & \\
\hline \multicolumn{4}{|l|}{ Certification Status } \\
\hline Permanent & 35 & & \\
\hline Professional & 17 & & \\
\hline Provisional & 24 & & \\
\hline
\end{tabular}

Note-Included in this present study are three types of teaching experience variables:

1. Career represents the total number of years of teaching experience. 2. Early childhood is defined as teaching from birth through the second grade (NYSED, 2015). 3. Other than ECE refers to years of teaching experience in grades other than from birth through the second grade (early childhood education)

up the emotional support domain (positive climate, negative climate, teacher sensitivity, and regard for student perspectives). Three dimensions make up the classroom organization domain (behavior management, productivity, and instructional learning formats). The final three dimensions make up the instructional support domain (concept development, quality of feedback, and language modeling), for a total of 10 dimensions. Trained and reliable CLASS observers were assigned to each EPK and UPK classroom. Each observer assigned a subjective score from 1 to 7 to each of the 10 dimensions. The scores range in a continuum of low-quality (one, two), medium (three, four, five), and high (six, seven) levels of quality.

Statistical Analysis. A series of multiple linear regression analyses were conducted to examine whether teacher demographic and outcome variables were predictive of teacher self-efficacy. Pearson correlation coefficients were analyzed to determine inter-correlations between teacher self-efficacy and teacher demographics.

\section{Results}

Table 2 depicts descriptive statistics and inter-correlations for the teacher variables included in the study. Overall teacher self-efficacy is one of the highest reported in any empirical study solitarily focused on preschool teachers (Bullock et al., 2015; Guo et al., 2011a, 2010; Kim \& Kim, 2010; Woolfolk Hoy \& Spero, 2005).

Years of teaching experience outside of the birth $-2^{\text {nd }}$ grade setting was negatively correlated to student engagement $(r=-.23)$, instructional support $(r=-.30)$, and overall teacher self-efficacy $(r=-.22)$. Overall teacher self-efficacy was positively correlated with job satisfaction $(r=.32)$ and location of employment (district or CBO teacher) $(r=.28)$. Job satisfaction was positively correlated to location of employment (district or CBO teacher) $(r=.44)$. The instructional support ( $r=.30)$ and classroom management $(r=.32)$ domains of teacher self-efficacy are significantly correlated to location of employment (district or CBO teacher). 
Table 2. Descriptive Statistics and Inter-correlations between Teacher Self-Efficacy and Teacher Variables

\begin{tabular}{|c|c|c|c|c|c|c|c|c|c|c|c|c|}
\hline Variable & M & SD & 1 & 2 & 3 & 4 & 5 & 6 & 7 & 8 & 9 & 10 \\
\hline Student Engagement & 7.5 & 1.5 & --- & $.86^{* *}$ & $.77^{* *}$ & $.94^{* *}$ & .14 & $.30 * \star$ & .0008 & .09 & $-.23^{*}$ & .18 \\
\hline Instructional Support & 7.5 & 1.0 & & - & $.77^{* *}$ & $.94^{\star *}$ & .20 & $.25^{\star}$ & .01 & .15 & $.30^{* *}$ & $.30^{*}$ \\
\hline Classroom Management & 7.3 & 1.1 & & & - & $.91^{*}$ & .20 & $.35^{\star \star}$ & .01 & .11 & -.11 & $.32^{* *}$ \\
\hline Overall Teacher Self-Efficacy & 7.4 & 1.0 & & & & - & .20 & $.32 * *$ & .01 & .13 & $-.22^{* *}$ & $.28^{*}$ \\
\hline Teacher Age & 41.0 & 13.5 & & & & & - & .22 & $.71^{* *}$ & $.71^{* *}$ & .19 & $.52^{* *}$ \\
\hline Job Satisfaction & 7.4 & 1.5 & & & & & & - & .17 & .18 & -.04 & $.44^{* \star}$ \\
\hline Career & 11.5 & 8.1 & & & & & & & & $.88^{* *}$ & .17 & $.35^{* \star}$ \\
\hline B-2nd Grade & 10.1 & 7.5 & & & & & & & & & .03 & $.31^{* *}$ \\
\hline Outside B-2nd & & & & & & & & & & & & -.06 \\
\hline District1 or CBO2 Teacher & & & & & & & & & & & & --- \\
\hline
\end{tabular}

Note. $N=81 .{ }^{*} p<.01, * p<.05, N^{1}=37, N^{2}=44$

A multiple regression analysis was conducted to examine the relationship between teacher self-efficacy, teacher variables, and teacher outcomes. The variables included in the regression models are the variables that were statistically significantly correlated with teacher self-efficacy in Table 2. The results are shown in Table 3. Overall teacher self-efficacy served as the dependent variable for the regression model. Model one included years of teaching experience outside the birth-2 ${ }^{\text {nd }}$ grade setting. Model two included job satisfaction. Model three included location of employment (district vs. CBO). Model four included the three domains that make up the CLASS (emotional support, classroom organization, and instructional support).

The first regression model demonstrated that teaching experience outside of the birth $-2^{\text {nd }}$ grade setting was significantly associated with teacher self-efficacy $(\beta=-.232)$. The second regression model showed that when job satisfaction was added, it demonstrated a strong and significant association with teacher self-efficacy $(\beta=.294)$. The third regression model demonstrated that when location of employment was added to the model, location of employment demonstrated a non-significant association with teacher self-efficacy $(\beta=.169)$. The results of the fourth model demonstrated that the emotional support $(\beta=-.02)$, classroom organization $(\beta=.17)$, and instructional support ( $\beta=$.049) domains of the CLASS showed a non-significant association with teacher self-efficacy. The $\mathrm{R}^{2}$ of the model presented in Table 3 only accounts for $13 \%$ of the variance in predicting preschool teacher self-efficacy.

\section{Discussion}

The purpose of this study was to examine which, if any, teacher demographic or classroom variables are predictive of preschool teacher self-efficacy in an urban school district located in Western NY. We observed that years of teaching experience outside of the birth-2 ${ }^{\text {nd }}$ grade setting was a negative predictor of preschool teacher self-efficacy. Our regression model reported job satisfaction as a predictor of preschool teacher self-efficacy until employment was added to the model. A few important results were observed that have critical implications for what factors contribute to preschool teacher self-efficacy.

\section{Factors associated with preschool teacher self-efficacy}

The student engagement, instructional support, and overall teacher self-efficacy variables were all moderately and significantly, although negatively, correlated to years of teaching experience outside of the early childhood classroom (birth-2 ${ }^{\text {nd }}$ grade). Guo et al. (2010) found that years of early childhood teaching experience was negatively correlated with teacher self-efficacy. One might assume that having more years of teaching experience in a birth- $2^{\text {nd }}$ grade classroom would provide the classroom teachers with the time to acquire the skill set that would permit them to be more efficacious in the EPK/UPK classroom.

Preschool teacher self-reported job satisfaction was associated with higher levels of teacher self-efficacy. This is

Table 3. Summary of Linear Regression Model Variables Predicting Preschool Teacher Self-Efficacy

\begin{tabular}{|c|c|c|c|c|c|c|c|c|}
\hline \multirow{2}{*}{ Variable } & \multicolumn{2}{|c|}{ Model 1} & \multicolumn{2}{|c|}{ Model 2} & \multicolumn{2}{|c|}{ Model 3} & \multicolumn{2}{|c|}{ Model 4} \\
\hline & $\beta$ & $t(1,79)$ & $\beta$ & $t(2,78)$ & $\beta$ & $t(3,77)$ & $\beta$ & $t(6,74)$ \\
\hline Outside Birth-2nd grade & $-0.232^{*}$ & -2.124 & $-0.218^{*}$ & -2.074 & $-0.212^{*}$ & -2.025 & $-0.212^{*}$ & -1.997 \\
\hline Job Satisfaction & & & $0.294^{* \star}$ & 2.793 & 0.219 & 1.884 & 0.212 & 1.802 \\
\hline District vs. CBO & & & & & 0.169 & 1.45 & 0.144 & 1.199 \\
\hline \multicolumn{9}{|l|}{ CLASS Variables } \\
\hline Emotional Support & & & & & & & -0.02 & -0.12 \\
\hline Classroom Org. & & & & & & & 0.17 & 0.982 \\
\hline Instructional Support & & & & & & & 0.049 & 0.334 \\
\hline F-Statistic & $4.511^{*}$ & & $6.351^{\text {** }}$ & & $4.995 * *$ & & $3.058^{* *}$ & \\
\hline Adjusted R2 & 0.042 & & 0.118 & & 0.13 & & 0.134 & \\
\hline
\end{tabular}

Note: ${ }^{* *} p<.01,{ }^{*} p<.05$ 
in line with research conducted by Avanzi and colleagues (2013), who reported that teacher self-efficacy was positively correlated to job satisfaction. Teachers with higher reported self-efficacy also experienced less burnout than their less efficacious peers. The participants of the Avanzi et al. (2013) study were a mix of primary, middle, and high school teachers.

Job satisfaction was found to be strongly and significantly correlated to place of employment $(r=.44)$. In the current study, EPK and UPK teachers in the sample were employed both by the public school and CBO's. A post hoc t-test analysis revealed that district school teachers are much more satisfied in their current position as compared to their peers employed by a CBO $(t=4.47, p<.01)$.

Both EPK and UPK teachers educating teachers within the school district or $\mathrm{CBO}$ are required to be certified to teach in birth-2 ${ }^{\text {nd }}$ grade classrooms, as well as hold at least a bachelor's degree in early childhood or childhood education (NYSED, 2016). Location of employment was moderately and significantly correlated to the instructional support, classroom management, and overall teacher self-efficacy variables. Similar to job satisfaction, a post hoc t-test analysis reported that teachers employed by the school district felt more efficacious than their peers employed by a CBO $(t=2.57, p<.05)$. It is interesting to note that Infurna et al., (2016) found that even though school district teachers were more satisfied with their jobs and reported higher levels of job satisfaction, there were no significant differences between the public school teacher and CBO teacher CLASS scores.

Three glaring differences exist between teachers employed by the school district and teachers employed by a CBO. First, teachers employed by the school district are paid significantly more than their peers teaching in a CBO. Second, teachers employed by the school district are able to invest in the New York State teachers' retirement system, whereas CBO teachers are not.

Finally, teachers employed by the school district are eligible for tenure after a pre-determined amount of years (typically after three or four years depending on previous teaching experience), CBO teachers are not eligible for tenure (NYSED, 2015).

It is important to mention contradictory results between our study and previously published studies that examined teacher self-efficacy and years of teaching experience in the preschool setting. Wolters and Daugherty (2007) found that preschool through $12^{\text {th }}$ grade teachers with more years of teaching experience reported higher levels of self-efficacy. The regression analysis in this study did not include career years of teaching experience or years of teaching experience in the birth- $2^{\text {nd }}$ grade setting because the variables failed to reach significance. The teachers examined by Wolters and Daugherty (2007) were all employed by a school district. That is not the case in our study.

We found that years of teaching experience outside of the birth to second grade classroom was associated with lower teacher self-efficacy. It is possible that a teacher who has many years of experience in the upper elementary grades (third through sixth) would not find the transition to the early childhood setting as rewarding.

The findings of this study suggest that a teacher with a great amount of experience in other grades besides birth$2^{\text {nd }}$ may find it difficult to transition to and find success in a preschool classroom. The school district in which this study was completed currently has a policy in which each spring teachers are able to transfer schools and grade levels if they wish and have enough seniority to do so. A teacher that may be struggling in a fifth grade classroom may, if they have the proper certification(s), transfer to a preschool classroom. However, based on the results of this study, this would prove to be fruitless because years of teaching experience outside of the birth- $2^{\text {nd }}$ grade setting were found to negatively predict preschool teacher self-efficacy. Future district policies are recommended to be put in place and executed in which a teacher outside of the birth-2 $2^{\text {nd }}$ grade setting should not be able to transfer into a preschool classroom unless absolutely necessary.

\section{Limitations and Conclusion}

There are a couple of limitations to note. First, the EPK and UPK teachers who participated in this study were all educating at-risk children living within the perimeter of the same urban school district. Therefore, it is not clear whether these findings about teachers' sense of self-efficacy are generalizable to other populations of EPK and UPK teachers in rural and suburban school districts. Second, this finding cannot be generalizable to similar samples of urban school district teachers. Future preschool teacher self-efficacy studies should be conducted with teachers in other urban school districts.

This research study carries important implications for preschool teacher self-efficacy. First, school districts should take into account the amount of years of teaching experience a teacher has outside of the birth- $2^{\text {nd }}$ grade setting. Teacher recruitment policy should take into consideration whether the teacher applying for the preschool teaching position has experience outside of the birth-2nd grade setting.

Second, the school district in which the CBO's are located should provide CBO teachers with opportunities for competitive wages, and if possible, opportunities to become members of the teacher retirement system, in the case of the present study, the state of New York. Perspective CBO teachers should be better informed about what may not be offered to them when accepting a teaching position outside of the school district.

\section{References}

Ashton, P. T., \& Webb, R. B. (1986). Making a difference: Teacher's sense of efficacy and student achievement. New York, NY: Longman.

Avanzi, L., Miglioretti, M., Velasco, V., Balducci, C., Vecchio, L., . . Skaalvik, E. (2013). Cross-validation of the Norwegian teacher's self-efficacy scale. Teaching and Teacher Education, 31, 69-78.

Brown, E. T. (2005). The influence of teachers' efficacy and beliefs regarding mathematics instruction in the early childhood classroom. Journal of Early Childhood Teacher Education, 26, 239-257.

Bullock, A., Coplan, R. J., \& Bosacki, S. (2015). Exploring links between early childhood educators' psychological characteristics and classroom management self-efficacy beliefs. Canadian Journal of Behavioral Science, 47(2), 175-183.

Chen, W. (2007). The structure of secondary school teacher job satisfaction and its relationship with attrition 
and work enthusiasm. Chinese Education and Society, 40(5), 17-31.

Cheung, H. Y. (2008). Teacher efficacy: A comparative study of Hong Kong and Shanghai primary in-service teachers. The Australian Educational Researcher, 35, 101-123.

Early, D. M., Maxwell, K. L., Burchinal, M., Alva, S., Bender, R. H., \& Bryant, D. (2007). Teachers' education, classroom quality, and young children's academic skills: Results from seven studies of preschool programs. Child Development, 78, 558-580.

Gibson, S., \& Dembo, M. (1984). Teacher efficacy: a construct validation. Journal of Educational Psychology, 76, 569-582.

Goddard, R. D., \& Goddard, Y. L. (2001). A multilevel analysis of the relationship between teacher and collective efficacy in urban schools. Teaching and Teacher Education, 17, 807-818.

Guo, Y., Justice, L. M., Sawyer, B., \& Tompkins, V. (2011a). Exploring factors related to teachers' self-efficacy. Teaching and Teacher Education, 27, 961-968.

Guo, Y., Piasta, S. B., Justice, L. M., \& Kaderavek, J. (2010). Relations among preschool teachers' self-efficacy, classroom quality and children's language and literacy gains. Teaching and Teacher Education, 26, 1094-1103.

Justice, L. M., Mashburn, A. J., Hamre, B. K., \& Pianta, R. C. (2008). Quality of language and literacy instruction in preschool classrooms serving at-risk pupils. Early Childhood Research Quarterly, 23, 51-68.

Kim, Y. H., \& Kim, Y. E. (2010). Korean early childhood educators' multi-dimensional teacher self-efficacy and ECE center climate and depression severity in teachers as contributing factors. Teaching and Teacher Education, 26, 1117-1123.

Klassen, R. M., \& Chiu, M. M. (2010). Effects on teacher self-efficacy and job satisfaction: Teacher gender, years of experience, and job stress. Journal of Educational Psychology, 102, 741-756.

Klassen, R. M., Bong, M., Usher, E. L., Chong, W. H., Huan, V., Wong, I. S. F., \& Georgiou, T. (2009). Exploring the validity of a teachers' self-efficacy scale in five countries. Contemporary Educational Psychology, 34, 67-76.

Lynch, R., \& Vaghul, K. (2015). The benefits and costs of investing in early childhood education: The fiscal, economic, and societal gains of a universal prekindergarten program in the United States, 2016-2050. Retrieved from www.equitablegrowth.org

Mashburn, A. J., Pianta, R. C., Hamre, B. K., Downer, J. T., Barbarin, O., \& Bryant, D. (2008). Measures of classroom quality in prekindergarten and children's development of academic, language, and social skills. Child Development, 79(3), 732-749.

Meisels, S. J. (2006). Accountability in early childhood: No easy answers. Chicago, IL: Erikson Institute, Herr Research Center for Children and Social Policy.

New York State Department of Education (NYSED). (2016). Universal pre-kindergarten allocations list. Retrieved from http://www.p12.nysed.gov/upk/documents/2016-2017UPKAllocationsList.pdf

New York State Department of Education (NYSED). (2015). Universal pre-kindergarten certification. Retrieved from http://www.p12.nysed.gov/upk/

Pianta, R. C., La Paro, K. M., \& Hamre, B. K. (2008). Classroom assessment scoring system: Pre-K. Baltimore, MD: Paul Brookes Publishing.

Skaalvik, E. M., \& Skaalvik, S. (2014). Teacher self-efficacy and perceived autonomy: Relations with teacher engagement, job satisfaction, and emotional exhaustion. Psychological Reports: Employment Psychology and Marketing, 114(1), 68-77.

Tschannen-Moran, M., \& Woolfolk Hoy, A. (2001). Teacher efficacy: Capturing an elusive construct. Teaching and Teacher Education, 17, 783-805.

Tschannen-Moran, M., \& Woolfolk Hoy, A. (2007). The differential antecedents of self-efficacy beliefs of novice and experienced teachers. Teaching and Teacher Education, 23, 944-956.

Tschannen-Moran, M., Woolfolk Hoy, A., \& Hoy, W. K. (1998). Teacher efficacy: Its meaning and measure. Review of Educational Research, 68, 202-248.

Van den Berg, R. (2002). Teachers' meaning regarding educational practice. Review of Educational Research, 72, 577-625.

Weiss, H. M. (2002). Deconstructing job satisfaction: Separating evaluations, beliefs and affective experiences. Human Resource Management Review, 22, 173-194.

Wolters, C. A., \& Daugherty, S. G. (2007). Goal structures and teachers' sense of efficacy: Their relation and 
association to teaching experience and academic level. Journal of Educational Psychology, 99(1), 181.

Woolfolk Hoy, A. E., \& Spero, R. B. (2005). Changes in teacher efficacy during the early years of teaching: A comparison of four measures. Teaching and Teacher Education, 21(4), 343-356. 
This page is intentionally left blank www.iejee.com 